\title{
Proceeding
}

8th INSHS International Christmas Sport Scientific Conference, 5-7 December 2013. International Network of Sport and Health

Science. Szombathely, Hungary

\section{Comparing the effect of endurance and resistance training on resting metabolic rate in a group of men with a sedentary lifestyle}

\author{
VOJTĚCH BASTYAN , JAN NOVOTNÝ, JAN MACH, VLADIMÍR POSPÍCHAL \\ ${ }^{1}$ Faculty of Sport Studies, Department of kinesiology, Brno, Czech Republic
}

\begin{abstract}
Bastyan, V., Novotný, J., Mach, J. \& Pospichal, V. (2014). Comparing the effect of endurance and resistance training on resting metabolic rate in a group of men with a sedentary lifestyle. J. Hum. Sport Exerc., 9(Proc1), pp.S376-S387. Study examined the effects of aerobic and anaerobic exercise on resting metabolic rate (RMR) and body composition and compared changes in these parameters in group of men $(n=17)$, aged 17-36, with sedentary lifestyle. During the initial measurements, the values of RMR, body composition and exercise test were obtained. In addition, five-day nutritional intake and record of physical activity were completed. After the initial measurements, subjects were randomly assigned in two training groups. Subjects in group EX1 $(n=9)$ performed aerobic physical activity - endurance training (jogging and/or running), whereas subjects in group EX2 $(n=8)$ performed anaerobic physical activity - resistance training. Physical activity was performed for 12 weeks, 3 times a week. The output measurements were obtained after 12 weeks of regular physical activity. Data of RMR were collected using the air analyzer Metalyzer Cortex 3B in the Laboratory of Sports Medicine, Faculty of Sports Studies in Brno. For body composition, method of bioelectrical impedance analysis has been used. RMR increased significantly from pre- to postraining for EX1 (2045,8 $\pm 207,5$ to $2168,8 \pm 217,7$ kcal.d-1) as well as for EX2 (1992 $\pm 164,4$ to $2340 \pm 321,3$ kcal.d-1). Body fat for EX1 was significantly reduced (21,2 $\pm 6,4$ to $18,7 \pm 6,8 \%$ ) compared with EX2 (22,4 $\pm 6,2$ to $20,6 \pm 7,6 \%)$. Measured data indicate more significant changes by subjects from EX1 group (endurance training). This study is a part of research for the dissertation of one of the authors and was financially supported from projects of specific research MUNI/A/0987/2011 and MUNI/A/0803/2012. Key words: RESTING METABOLIC RATE, BODY COMPOSITION, ENDURANCE TRAINING, RESISTANCE TRAINING, SEDENTARY LIFESTYLE.
\end{abstract}

\footnotetext{
Corresponding author. Faculty of Sport Studies, Department of kinesiology, Brno, Czech Republic

E-mail: vojta.basty@seznam.cz

8th INSHS International Christmas Sport Scientific Conference, 5-7 December 2013. International Network of Sport and Health Science. Szombathely, Hungary.

JOURNAL OF HUMAN SPORT \& EXERCISE ISSN 1988-5202

(c) Faculty of Education. University of Alicante

doi: 10.14198/jhse.2014.9.Proc1.23
}

VOLUME 9 |Proc1 | 2014 | S376 


\section{INTRODUCTION}

Lack of physical activity (PA) and excess of energy intake are the result of the presence of a number of health complications that may lead to the development of metabolic syndrome. This disease affects up to $30 \%$ of European and North American population and belongs among the risks for developing diseases, that are among the most frequent causes of death in this population. The occurrence of metabolic syndrome is closely linked to the upward trend in the prevalence of overweight and obesity, which is becoming a global problem and it is estimated, that in the year 2015, the world's population will include 700 million obese people over the age of 15 years (Kunešová et al., 2011). Czech Republic is no exception to this trend and more than half of the population is obese or overweight (Hainer, 2011).

Obesity occurs as a result of positive energy balance when energy intake exceeds energy expenditure. Energy intake is affected by the amount and kind of consumed nutrients. Energy expenditure consists of RMR, postprandial thermogenesis and energy expenditure during physical activity (Volpe et al., 2011). Resting metabolic rate accounts for $60-75 \%$ of total energy expenditure in sedentary people (Ravussin \& Bogardus, 1989). Therefore, it is major determinant of energy balance and even its small change may influence body weight management.

It is generally agreed, that regular physical activity increases the value of RMR, but the results presented in studies are not uniform. This study evaluates the influence of either endurance or resistance training on RMR and body composition in group of men $(n=17)$, aged $27-36$ with sedentary lifestyle.

\section{METHODS}

\section{Participants}

Seventeen healthy men aged $27-36$ participated in this study. Basic anthropometric characteristic is part of the results. In long-term, they do not perform any physical exercise and have sedentary job. They do not suffer from any metabolic or hormonal disorders, disorder of digestion, absorption, all without chronic kidney or liver disease. All subjects participated in baseline examination and measurement (pretraining measurement) and in measurement after 3-months of physical exercise program (posttraining measurement). Analysis of body composition and resting metabolic rate were taken by each of the subjects. After the initial measurements, subjects were randomly assigned in two training groups. Subjects in group EX1 $(n=9)$ performed aerobic physical activity - endurance training (jogging and/or running), whereas subjects in group EX2 $(n=8)$ performed anaerobic physical activity - resistance training. To help to create the training program, an exercise test was done by subjects from EX1. Initial level of aerobic capacity (VO2max) was $\bar{x}=45,57 \pm 5,62$. Due of unwillingness of subjects to perform second exercise test, we were unable to obtain the output values of VO2max.

Record of physical activity was evaluated, sedentary lifestyle dominated in all subjects. Assesment of energy intake was recorded aswell, subjects were told to not change their dietary habits.

\section{Statistical analysis}

Data were processed in the program STATISTICA CZ 10, after initial testing of normality of data distribution, the non-parametric statistical test - Wilcoxon signed-rank test was selected. For correlation, spearman's rank correlation coefficient has been used. 
Resting metabolic rate

The air analyzer Metalyzer Cortex 3B was used to measure the RMR. This device measures RMR using indirect calorimetry.

Before measuring, instrument calibration has been performed according to the manufacturer's instructions.

Before measuring, subjects followed these instructions: quiet night, approx. 8 hours of sleep, without the consumption of food and drink, except water, for 12 - hours, no physical exercise or exhaustive work for 48 hours. Resting metabolism was measured between 6:00 and 08:00 AM. Subjects were transported by motor vehicles, to ensure minimal physical activity. After entering the laboratory, subjects had rest in supine position for 30 minutes. Subjects remained in supine position during the measurement aswell. The measurement was finished when subject has reached the steady state. Steady state was defined as a situation, when there are no changes in the values of $\mathrm{O} 2$ and $\mathrm{CO} 2$ volumes in the range of $10 \%$, and the respiratory quotient remains unchanged in the range of $5 \%$.

Resting metabolic rate expresses metabolism in resting conditions, its value is about $10 \%$ higher than the value of basal metabolic rate. Methodology for measuring RMR was established because the basal metabolism is very difficult to measure.

\section{Body Composition Analysis}

Body weight and body composition were determined on body composition analyzer InBody 230, which detects human body composition by bioelectrical impedance. Investigated parameters were body height, body weight, percent of body fat (\%BF), fat free mass (FFM), muscle mass (MM) and fat mass (FM).

Measurements were done between 6:00 and 8:00 AM. Before the measurement, all subjects had quiet night, approx. 8 hours of sleep. They did not consume any food or drink, except water, for 12 - hours. Subjects completed three measurements in intervals of about five minutes. The final result was the arithmetic average of the three measurements.

\section{Exercise test}

Subjects from group EX1 completed a graded exercise test to exhaustion on a treadmill. The air analyzer Metalyzer Cortex 3B was used to observe and obtain esential indicators - heart rate, VO2max and ventilatory-anaerobic treshold.

After a short warm-up period followed the test. The initial speed was $7 \mathrm{~km} / \mathrm{h}$. Each subsequent minute, the speed increased by $1 \mathrm{~km} / \mathrm{h}$. The test was completed when subject reached volitional exhaustion.

\section{Training program}

After completing all pretesting, each subject participated for 12 weeks in supervised training program. Subjects trained 3 days/wk. Subjects from EX1 performed endurance training - jogging and running. Because of previous physical hypoactivity, training of extensive endurance was chosen and subjects exercised in heart rate zone characteristic for this kind of endurance, ie. between $70-85 \%$ of heart rate at the level of anaerobic threshold. And used for its activity combination of free weights (dumbbells) and exercise machines. All major muscle groups were involved in the training. During the first 6 weeks of training program, subjects performed 10-12 repetitions per set, 2-3 sets per exercise movement, 2 exercises per muscle group (thighs 3 , calves 1 ). The resistance was set on each exercise so that each subject became fatigued between 10 and 12 repetitions. During the second 6 weeks, subjects performed 8- 
10 repetitions per set, 3 sets per exercise movement, 2-3 exercises per muscle group. The resistance was set on each exercise so that each subject became fatigued between 8 and 10 repetitions. Fatigue was defined as the point when another repetition cannot be done properly in the full range of motion.

\section{RESULTS}

Resting metabolic rate - EX1 - endurance training

The results of absolute values of RMR for the pre- and posttraining measurement periods are presented in Table 1. Except of one subject, results showed increases in absolute value of RMR (expressed in kcal.d-1) from baseline to 3 months.

Increase in relative values of RMR (expressed in kcal.kg-1.d-1) was observed by all subjects (Table 2).

Values of pretraining and posttraining RMR were compared using Wilcoxon signed-rank test. The results show a significant increase in both absolute and relative values of RMR (Table 3 and Table 4).

Table 1. Absolute values of RMR and its changes (EX1)

\begin{tabular}{|c|c|c|c|}
\hline & Pretraining RMR (kcal.d $\left.{ }^{-1}\right)$ & Posttraining RMR (kcal.d. $\left.{ }^{-1}\right)$ & $\Delta \%$ \\
\hline Subject 1 & 2110 & 2324 & 10,1 \\
\hline Subject 2 & 2224 & 2225 & 0 \\
\hline Subject 3 & 2117 & 2332 & 10,2 \\
\hline Subject 4 & 1794 & 1897 & 5,7 \\
\hline Subject 5 & 2373 & 2371 & $-0,1$ \\
\hline Subject 6 & 1957 & 2293 & 17,2 \\
\hline Subject 7 & 1727 & 1772 & 2,6 \\
\hline Subject 8 & 2237 & 2358 & 5,4 \\
\hline Subject 9 & 1873 & 1947 & 4 \\
\hline $\mathbf{m}_{\mathbf{e}}$ & $\mathbf{2 1 1 0}$ & $\mathbf{2 2 9 3}$ & $\mathbf{5 , 4}$ \\
\hline
\end{tabular}

Table 2. Relative values of RMR and its changes (EX1)

\begin{tabular}{|c|c|c|c|}
\hline & Pretraining RMR $\left(\mathrm{kcal} \mathrm{kg}^{-1} \cdot \mathrm{d}^{-1}\right)$ & Posttraining RMR $\left(\mathrm{kcal}_{\mathrm{kg}}{ }^{-1} \cdot \mathrm{d}^{-1}\right)$ & $\Delta \%$ \\
\hline Subject 1 & 20,4 & 23,4 & 14,7 \\
\hline Subject 2 & 24 & 26,3 & 9,6 \\
\hline Subject 3 & 23,8 & 27,1 & 13,9 \\
\hline Subject 4 & 25,3 & 27,1 & 7,1 \\
\hline Subject 5 & 27 & 27,7 & 2,3 \\
\hline Subject 6 & 23,3 & 27,4 & 17,6 \\
\hline Subject 7 & 26,8 & 28,2 & 5,2 \\
\hline Subject 8 & 23,9 & 26 & 8,8 \\
\hline Subject 9 & 24,3 & 25,2 & 3,7 \\
\hline $\mathbf{m}_{\mathbf{r}}$ & $\mathbf{2 4}$ & $\mathbf{2 7 , 1}$ & $\mathbf{8 , 3}$ \\
\hline
\end{tabular}


Table 3. Absolute values of RMR - Wilcoxon test (EX1)

\begin{tabular}{|c|c|c|c|c|}
\hline & $\begin{array}{l}\text { Pretraining RMR } \\
{\left.\text { (kcal. } \mathrm{d}^{-1}\right)}^{-1}\end{array}$ & $\begin{array}{c}\text { Posttraining } \\
\left.\text { RMR (kcal } \mathrm{d}^{-1}\right)\end{array}$ & $\begin{array}{c}\text { Wilcoxon } \\
\text { Z }\end{array}$ & $\mathrm{p}$ \\
\hline $\mathrm{m}_{\mathrm{e}}$ & 2110 & 2293 & 2,428630 & 0,015157 \\
\hline
\end{tabular}

Table 4. Relative values of RMR - Wilcoxon test (EX1)

\begin{tabular}{|c|c|c|c|c|}
\hline & $\begin{array}{c}\text { Pretraining RMR } \\
\left(\mathrm{kcal}^{-1 . \mathrm{kg}^{-1}} \cdot \mathrm{d}^{-1}\right)\end{array}$ & $\begin{array}{c}\text { Posttraining RMR } \\
\left(\mathrm{kcal}^{-1} \mathrm{~kg}^{-1} \cdot \mathrm{d}^{-1}\right)\end{array}$ & $\begin{array}{c}\text { Wilcoxon } \\
\mathrm{Z}\end{array}$ & $\mathrm{p}$ \\
\hline $\mathrm{m}_{\mathrm{z}}$ & 24 & 27,1 & 2,665570 & $\mathbf{0 , 0 0 7 6 8 6}$ \\
\hline
\end{tabular}

Resting metabolic rate - EX2 - resistance training

The results of absolute and relative values of RMR for the pre- and posttraining measurement periods are presented in Table 5 and Table 6. Except of one subject in absolute value of RMR, results showed increases in both absolute value of RMR and relative value of RMR from baseline to 3 months.

Values of investigated parameters were compared using the non-parametric test (Wilcoxon signed-rank test). Results showed significant increases in both absolute value of RMR and relative value of RMR from baseline to 3 months (Table 7 and Table 8).

Table 5. Absolute values of RMR and its changes (EX2)

\begin{tabular}{|c|c|c|c|}
\hline & Pretraining RMR $\left(\mathrm{kcal}^{-1}{ }^{-1}\right)$ & Posttraining RMR $\left(\mathrm{kcal}^{-1}{ }^{-1}\right)$ & $\Delta \%$ \\
\hline Subject 1 & 1923 & 2132 & 10,9 \\
\hline Subject 2 & 2286 & 2882 & 26,7 \\
\hline Subject 3 & 2107 & 2434 & 15,5 \\
\hline Subject 4 & 2147 & 2640 & 23 \\
\hline Subject 5 & 1769 & 1761 & $-0,5$ \\
\hline Subject 6 & 1903 & 2164 & 13,7 \\
\hline Subject 7 & 1819 & 2255 & 24 \\
\hline Subject 8 & 1980 & 2158 & 9 \\
\hline $\mathbf{m}_{\mathbf{e}}$ & $\mathbf{1 9 5 1 , 5}$ & $\mathbf{2 2 0 9 , 5}$ & $\mathbf{1 4 , 6}$ \\
\hline
\end{tabular}


Table 6. Relative values of RMR and its changes (EX2)

\begin{tabular}{|c|c|c|c|}
\hline & Pretraining RMR $\left(\mathrm{kcal}^{\mathrm{kg}} \mathrm{k}^{-1} \cdot \mathrm{d}^{-1}\right)$ & Posttraining RMR $\left(\mathrm{kcal} \mathrm{kg}^{-1} \cdot \mathrm{d}^{-1}\right)$ & $\Delta \%$ \\
\hline Subject 1 & 24,9 & 26,5 & 6,4 \\
\hline Subject 2 & 22,5 & 27,9 & 24 \\
\hline Subject 3 & 21,8 & 25 & 14,7 \\
\hline Subject 4 & 16,3 & 19,7 & 20,9 \\
\hline Subject 5 & 25,6 & 26 & 1,6 \\
\hline Subject 6 & 24,8 & 29,6 & 19,4 \\
\hline Subject 7 & 23,8 & 31,1 & 30,7 \\
\hline Subject 8 & 23,7 & 26,1 & 10,1 \\
\hline $\mathbf{m}_{e}$ & $22,9 \pm 2,8$ & $26,5 \pm 3,2$ & $16 \pm 9$ \\
\hline
\end{tabular}

Table 7. Absolute values of RMR - Wilcoxon test (EX2)

\begin{tabular}{|c|c|c|c|c|}
\hline & $\begin{array}{c}\text { Pretraining RMR } \\
\left(\mathrm{kcal} \mathrm{d}^{-1}\right)\end{array}$ & $\begin{array}{c}\text { Posttraining RMR } \\
\left(\mathrm{kcal} \mathrm{d}^{-1}\right)\end{array}$ & $\begin{array}{c}\text { Wilcoxon } \\
\mathrm{Z}\end{array}$ & $\mathrm{p}$ \\
\hline $\mathrm{m}_{\mathrm{s}}$ & 1951,5 & 2209,5 & 2,380476 & $\mathbf{0 , 0 1 7 2 9 1}$ \\
\hline
\end{tabular}

Table 8. Relative values of RMR - Wilcoxon test (EX2)

\begin{tabular}{|c|c|c|c|c|}
\hline & $\begin{array}{c}\text { Pretraining RMR } \\
\left(\mathrm{kcal}_{\mathrm{kg}}^{-1} \cdot \mathrm{d}^{-1}\right)\end{array}$ & $\begin{array}{c}\text { Posttraining RMR } \\
\left(\mathrm{kcal}^{\mathrm{k} \mathrm{kg}^{-1}} \cdot \mathrm{d}^{-1}\right)\end{array}$ & $\begin{array}{l}\text { Wilcoxon } \\
\mathrm{Z}\end{array}$ & $\mathrm{p}$ \\
\hline $\mathrm{m}_{\mathrm{s}}$ & $22,9 \pm 2,8$ & $26,5 \pm 3,2$ & 2,520504 & $\mathbf{0 , 0 1 1 7 1 9}$ \\
\hline
\end{tabular}

Body composition - EX1 - endurance training

The body composition results for the pre- and posttraining measurments are presented in Table 9 and 10. All subjects showed decreases in percentage of body fat (BF) and total fat mass (FM) from baseline to 3 months. Other studied parameters were height, weight, muscle mass (MM) and fat free mass (FFM).

After comparing using Wilcoxon test, a significant decrease in the percentage of body fat has been found (Table 11). 
Table 9. Pretraining body composition (EX1)

\begin{tabular}{|l|c|c|c|c|c|c|}
\hline & Height (cm) & Weight (kg) & $\%$ BF & MM (kg) & FFM (kg) & FM (kg) \\
\hline Subject 1 & 192 & 103,4 & 21,6 & 46,7 & 81 & 22,4 \\
\hline Subject 2 & 171 & 92,5 & 30,9 & 36,5 & 64 & 28,5 \\
\hline Subject 3 & 182 & 89 & 17,7 & 42,2 & 73,2 & 15,8 \\
\hline Subject 4 & 174 & 71 & 21,4 & 31,6 & 55,8 & 15,2 \\
\hline Subject 5 & 189 & 88 & 11 & 45,2 & 78,3 & 9,7 \\
\hline Subject 6 & 179 & 83,8 & 31,3 & 32,3 & 57,6 & 26,2 \\
\hline Subject 7 & 169 & 64,4 & 19,2 & 29,2 & 52 & 12,4 \\
\hline Subject 8 & 1,95 & 93,7 & 17,9 & 44,1 & 76,9 & 16,8 \\
\hline Subject 9 & 1,71 & 77,2 & 20,1 & 35,3 & 61,7 & 15,5 \\
\hline
\end{tabular}

Table 10. Posttraining body composition (EX1).

\begin{tabular}{|l|c|c|c|c|c|c|}
\hline & Height (cm) & Weight (kg) & $\%$ BF & MM (kg) & FFM (kg) & FM (kg) \\
\hline Subject 1 & 192 & 99,3 & 17,7 & 47,1 & 81,7 & 17,6 \\
\hline Subject 2 & 171 & 84,4 & 27 & 35 & 61,6 & 22,8 \\
\hline Subject 3 & 182 & 86 & 16,9 & 41,2 & 71,5 & 14,5 \\
\hline Subject 4 & 174 & 69,9 & 17,8 & 32,8 & 57,4 & 12,5 \\
\hline Subject 5 & 189 & 85,6 & 7,3 & 46 & 79,3 & 6,3 \\
\hline Subject 6 & 179 & 83,7 & 30,8 & 32,5 & 57,9 & 25,8 \\
\hline Subject 7 & 169 & 62,8 & 17,4 & 29,2 & 51,9 & 10,9 \\
\hline Subject 8 & 195 & 90,8 & 15 & 44,3 & 77,2 & 13,6 \\
\hline Subject.9 & 171 & 77,4 & 18 & 36,6 & 63,5 & 13,9 \\
\hline
\end{tabular}

Table 11. Percentage of body fat - Wilcoxon test (EX1).

\begin{tabular}{|c|c|c|c|c|}
\hline & $\begin{array}{c}\text { pretraining } \\
\text { body fat }(\%)\end{array}$ & $\begin{array}{c}\text { posttraining } \\
\text { body fat (\%) }\end{array}$ & Wilcoxon & $\mathrm{z}$ \\
\hline $\mathrm{m}_{\mathrm{s}}$ & 20,1 & 17,7 & 2,665570 & $\mathbf{0 , 0 0 7 6 8 6}$ \\
\hline
\end{tabular}

Body composition - EX2 - resistance training

The body composition results for the pre- and posttraining measurments are presented in Table 12 and Table 13. All subjects showed increases in fat free mass from baseline to 3 months. Results in changes of fat mass and percentage of fat mass are not uniform, some of the subjects showed decrease in fat mass, whereas the gain of fat mass was observed by others.

We have not found a significant decrease in percentage of body fat after using Wilcoxon test (Table 14). 
Table 12. Pretraining body composition (EX2).

\begin{tabular}{|l|c|c|c|c|c|c|}
\hline & $\begin{array}{c}\text { Heigh } \\
(\mathrm{cm})\end{array}$ & Weigh (kg) & \%BF & FFM (kg) & MM (kg) & FM (kg) \\
\hline Subject 1 & 1,83 & 77,3 & 13,9 & 66,6 & 38 & 10,7 \\
\hline Subject 2 & 1,8 & 101,4 & 30 & 71 & 40,9 & 30,4 \\
\hline Subject 3 & 1,82 & 96,5 & 21 & 76,2 & 43,8 & 20,3 \\
\hline Subject 4 & 194 & 132,1 & 31,5 & 90,5 & 52,1 & 41,6 \\
\hline Subject 5 & 173 & 69,1 & 18,7 & 56,2 & 31,9 & 12,9 \\
\hline Subject 6 & 180 & 76,6 & 25,9 & 56,7 & 32 & 19,9 \\
\hline Subject 7 & 181 & 76,5 & 16,9 & 63,6 & 36,6 & 12,9 \\
\hline Subject 8 & 183 & 83,4 & 21,1 & 65,8 & 37,6 & 17,6 \\
\hline
\end{tabular}

Table 13. Posttraining body composition (EX2)

\begin{tabular}{|l|c|c|c|c|c|c|}
\hline & $\begin{array}{c}\text { Heigh } \\
(\mathrm{cm})\end{array}$ & Weigh (kg) & \%BF & FFM (kg) & MM (kg) & FM (kg) \\
\hline Subject 1 & 1,83 & 80,4 & 14,2 & 69 & 40,6 & 11,4 \\
\hline Subject 2 & 1,8 & 103,3 & 30,3 & 72 & 41,5 & 31,3 \\
\hline Subject 3 & 1,82 & 97,5 & 21,8 & 76,3 & 44 & 21,2 \\
\hline Subject 4 & 194 & 134,1 & 31,7 & 91,5 & 52,9 & 42,6 \\
\hline Subject 5 & 173 & 67,7 & 15 & 57,5 & 32,6 & 10,2 \\
\hline Subject 6 & 180 & 73,2 & 22,6 & 56,6 & 31,8 & 16,6 \\
\hline Subject 7 & 181 & 72,4 & 10,4 & 64,9 & 37,3 & 7,5 \\
\hline Subject 8 & 183 & 82,8 & 19 & 67,1 & 38,4 & 15,7 \\
\hline
\end{tabular}

Table 14. Percentage of body fat - Wilcoxon test (EX2)

\begin{tabular}{|c|c|c|c|c|}
\hline & Pretraining \%BF & Postraining \%BF & $\begin{array}{c}\text { Wilcoxon } \\
\text { Z }\end{array}$ & p \\
\hline $\bar{x}$ & $22,4 \pm 6,2$ & $20,6 \pm 7,6$ & 1,120224 & 0,262619 \\
\hline
\end{tabular}

Correlation between resting metabolic rate and fat free mass

During the pretraining measurement, a significant positive correlation between RMR and FFM was found in both experimental groups. In group EX1, Spearman's rank correlation coefficient was 0,8 (figure 1). In group EX2, performing resistance training, 0,88 for Spearman's rank correlation coefficient was measured (figure 2).

After 3 months of regular training, we have still observed positive correlation in both groups. In group EX1, a significant correlation and spearman's rank correlation coefficient 0,83 has been found (figure 3 ), whereas this dependance is not significant in group EX2, spearman's rank correlation coefficient was measured as 0,64 in this case (figure 4). 


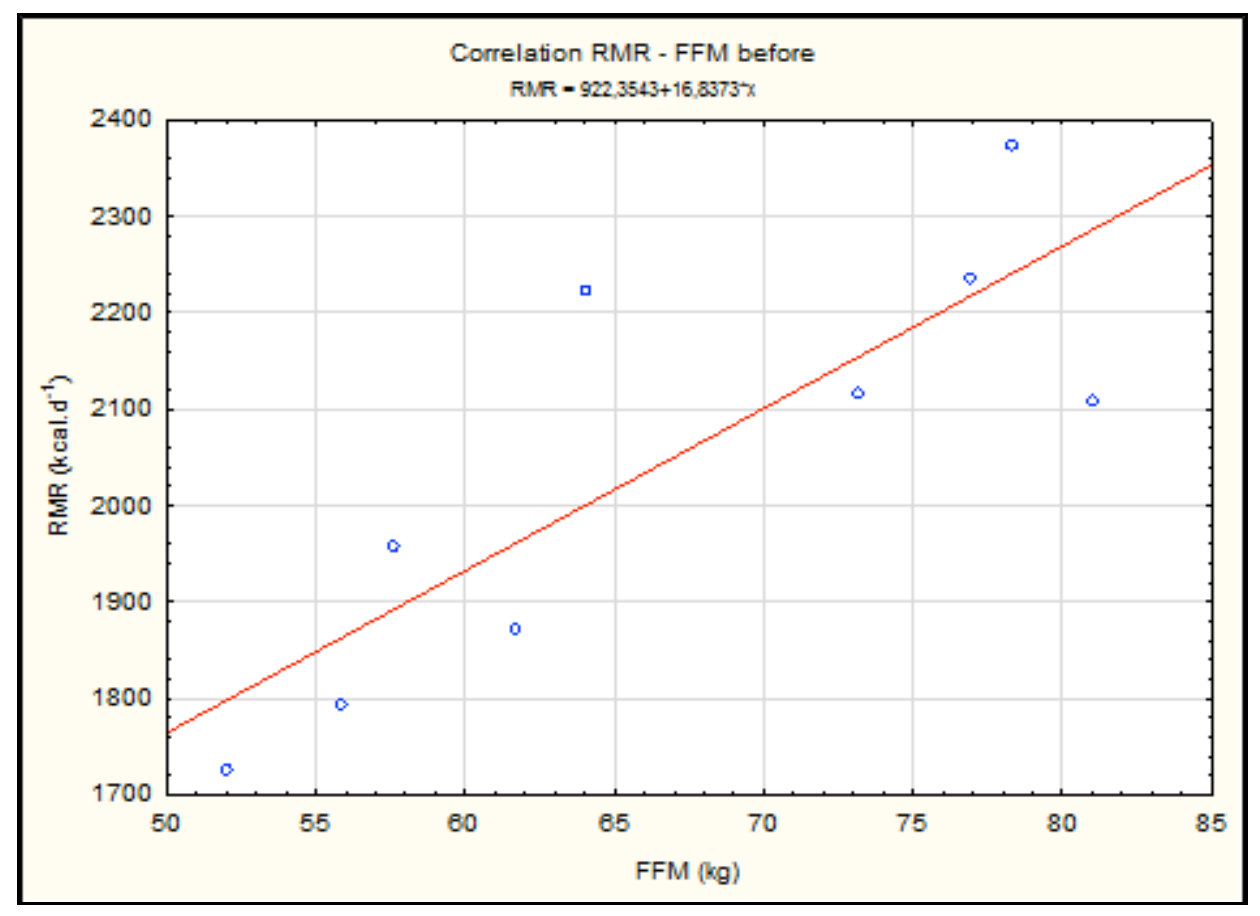

Figure 1. Spearman's rank correlation coefficient - pretraining EX1

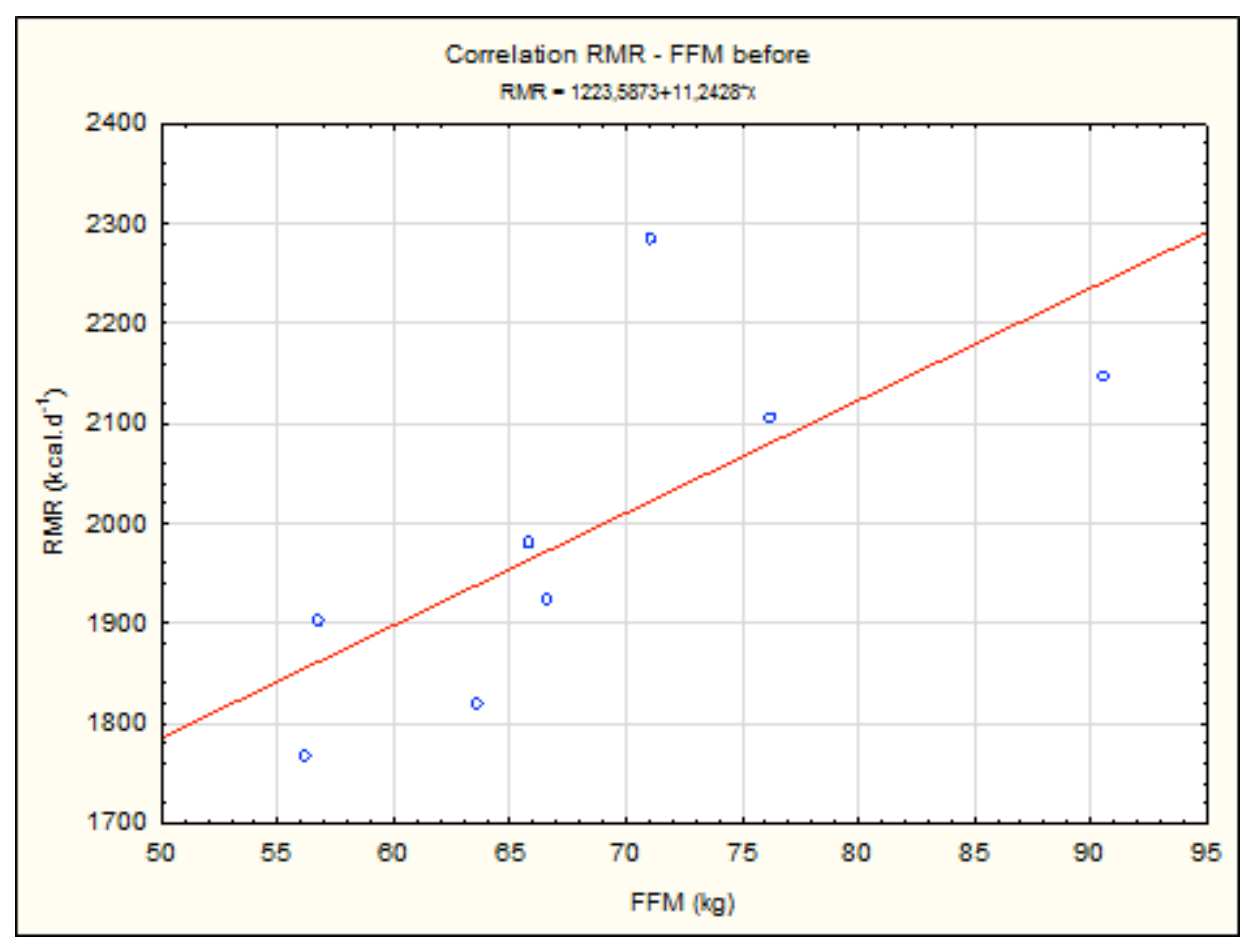

Figure 2. Spearman's rank correlation coefficient - pretraining EX2 


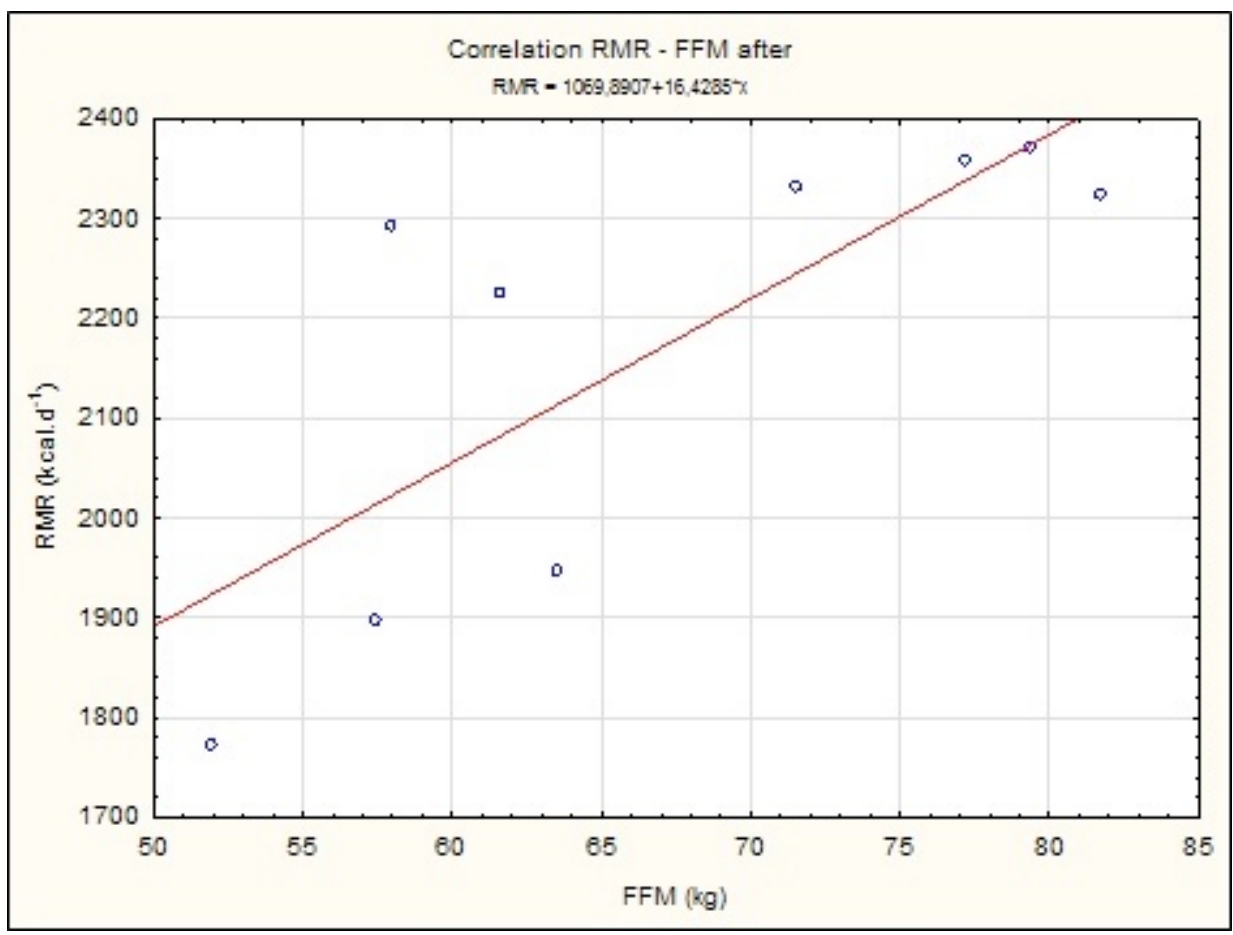

Figure 3. Spearman's rank correlation coefficient - posttraining EX1

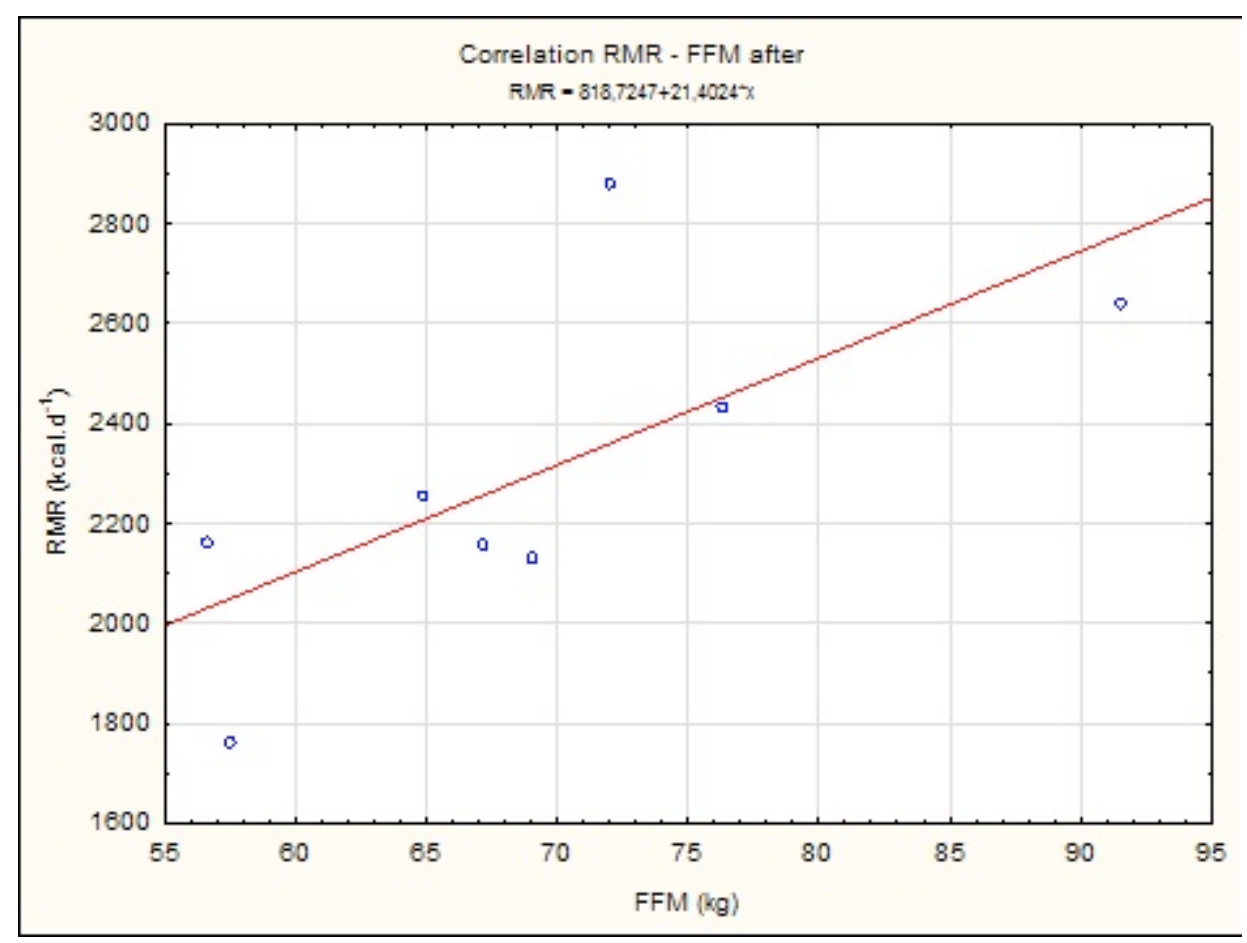

Figure 4. Spearman's rank correlation coefficient - posttraining EX2 


\section{DISCUSSION}

The results of this study indicate that absolute RMR and relative RMR expressed as increased significantly over the 12 week training period in both experimental groups. These results do not agree with study of Dolezal \& Potteiger (1998), where the results showed significant increase in both absolute and relative RMR over the 10-wk resistance training period, but, in contrary to our results, significant decrease in value of RMR in group performing endurance exercise was observed. The study of Geliebtera et al. (1997), shows a decrease in RMR aswell, but this result is probably connected with the decrease of energy intake and loss of fat free mass. The slight decrease in the value of RMR also recorded other studies (Byrne \& Wilmore, 2001, Santa Clara et al., 2006). Study of Lee et al. (2009), in which a group of nine men, aged 1932 years, performed endurance exercise, did not record any significant change either in absolute or in relative value of RMR. The results of other studies showed the value of RMR as unchanged aswell (Keytel et al., 2001; Meredith et al., 1989). Potteiger et al. (2008) recorded an increase in RMR and decrease in percentage of body fat in their study, in which 31 overweight men were involved (15 performed endurance exercise, 16 resistance training). Our results also support other studies (Ballor \& Poehlman, 1992; Berke et al., 1992; Broeder et al., 1992). It is clear, that the issue of the impact of physical activity on RMR includes a variety of individual factors such as the kind and intensity of exercise, nutrition during the intervention program, gender, age and previous physical activity of subjects and more.

It is generally agreed, that there is strong relationship between resting metabolic rate and fat free mass. In our study, the spearman's rank correlation coefficient was lower and correlation not significant after 3 months of resistance training, whereas before the training, significant correlation was found in the same group. In group performing endurance exercise, significant correlation was observed before as well as after the training.

\section{CONCLUSIONS}

After completing three months of regular exercise, we have found significant increase in absolute and relative value of RMR in both groups. These changes are more obvious in the case of group performing endurance training.

We have found inconsistencies in the gain and loss of muscle mass in endurance group, however, we can observe a significant decrease in percent body fat. In resistance group, some subjects showed decrease in fat mass in contrary to others, where the gain of fat mass was observed. Same situation was observed in case of percentage of body fat. We have not found significant decrease in percentage of body fat.

\section{REFERENCES}

1. Ballor, D.L. \& Poehlman, E.T. (1992). Resting metabolit rate and coronary disease risk factors in aerobically and resistance trained women. The American Journal of Clinical Nutrition, 56, pp.968974.

2. Berke, E., Gardner, A.W., Goran, M.I. \& Poehlman, E.T. (1992). Resting metabolit rate and the influence of the pretesting environment. The American Journal of Clinical Nutrition, 55, pp.626-629.

3. Breoder, C.E., Burrhus, K.A., Svanevik, L.S. \& Wilmore, J.H. (1992). The effects of either highintensity resistance or endurance training on resting metabolit rate. The American Journal of Clinical of Nutrition, 55, pp.802-810. 
4. Byrne, H.K. \& Wilmore, J.H. (2001). The effects of high intensity of a 20-week exercise training program on resting metabolit rate in previously sedentary moderately obese women. International Journal of sport Nutrition and Exercise Metabolism, 11, pp.15-31.

5. Dolezal, A.B. \& Potteiger, A.J. (1998). Concurrent resistance and endurance training influence basal metabolic rate in nondieting individuals. Journal of Applied Phzsiology, 85, pp.695-700.

6. Geliebter, A., Maher, M.M., Gerac, L., Gutin, B., Heymsfield, S.B. \& Hashim, S.A. (1997). Effects of strenght or aerobic training on body composition, resting metabolit rate, and peak oxygen consumption in obese dieting subjects. The American Journal of Clinical of Nutrition, 66, pp.557563.

7. Hainer, V. (2011a). Farmakoterapie obezity. In Hainer, V. Základy klinické obezitologie. (2., přeprac. a dopl. vyd., s. 277-300). Praha: Grada.

8. Hainer, V. (2011b). Obezita v historii lidstva. In Hainer, V. Základy klinické obezitologie. (2., přeprac. a dopl. vyd., s. 1-14). Praha: Grada.

9. Keytel, L.R., Lambert, M.I., Johnson, J., Noakes, T.D. \& Lambert, E.V. (2001). Free living energy expenditure in post menopausal women before and after exercise training. International Journal of Sport Nutrition and Sport Metabolism, 11, pp.226-237.

10. Kunešová, M., Müllerová, D. \& Hainer, V. (2011). Epidemiologie a zdravotní rizika obezity. In Hainer, V. Základy klinické obezitologie. (2., přeprac. a dopl. vyd., s. 15-34). Praha: Grada.

11. Lee, M., Sedlock, D.A., Flynn, M.G. \& Kamimorl, G.H. (2009). Resting metabolic rate after endurance exercise training. Medicine \& Science in Sport \& Exercise, 41, pp.1444-1451.

12. Meredith, C.N., Frontera, W.R., Fisher, E.C., Hughes, V.A. \& Herland, J.C. (1989). Peripheral effects of endurance training in young and old subjects. Journal of Applied Physiology, 66, pp.2844-2849.

13. Potteiger, A.J., Kirk, P.E., Jacobsen, J.D. \& Donnelly, E.J. (2008). Changes in resting metabolic rate and substrate oxidation after 16 months of exercise training in overweight adults. International Journal of Sport Nutrition and Exercise Metabolism, 18, pp.79-95.

14. Ravussin, E. \& Bogardus, C. (1989). Relationship of genetics, age, and physical fitness to daily energy expenditure and fuel utilization. The American Journal of Clinical Nutrition, 49, pp.968-975.

15. Santa-Clara, H., Szymanski, L.M., Ordille, T. \& Fernhall, B. (2006). Effects of exercise training on resting metabolit rate in postmenopausal African American and Caucasian women. Metabolism, 55, pp.1358-1364

16. Volp, A.C.P. et al. (2011). Energy expenditure: components and evaluation methods. Nutrición hospitalaria, 26(3), pp.430-440. 